\title{
Lumbosciatica in Consultation in Neurology, University Hospital of Cocody Epidemiologic, Clinical, Therapeutic and Evolutionary Aspects
}

\author{
Amon-Tanoh Muriel, Assi Berthe*, Kouamé-Assouan Ange Eric, Yapo-Ehounoud Constance, \\ Tanoh Christian
}

University Felix Houphouet Boigny, Abidjan, Ivory Coast, Côte d'Ivoire

Email: *Berthassi2000@gmail.com

How to cite this paper: Muriel, A.-T., Berthe, A., Eric, K.-A.A., Constance, Y.-E. and Christian, T. (2016) Lumbosciatica in Consultation in Neurology, University Hospital of Cocody Epidemiologic, Clinical, Therapeutic and Evolutionary Aspects. Open Access Library Journal, 3: e2787. http://dx.doi.org/10.4236/oalib.1102787

Received: July 17, 2016

Accepted: October 22, 2016

Published: October 25, 2016

Copyright $\odot 2016$ by authors and Open Access Library Inc.

This work is licensed under the Creative Commons Attribution International

License (CC BY 4.0).

http://creativecommons.org/licenses/by/4.0/

\begin{abstract}
The lumbosciatica, lumbo-neuralgic pain, is common. Their mechanisms are diverse. They are degenerative, infectious, inflammatory, tumoral, and traumatic. Their recurrence and their disabling aspect are responsible for a significant social and occupational disability, which is a cause of absenteeism. Our objective in this paper was to describe the epidemiological, clinical, paraclinical, therapeutic and evolutionary aspect of patients received in consultation. Method of Study: This transversal retrospective and descriptive study was conducted from December 2014 to February 2015 in Neurology Consultation at the University Hospital of Cocody. It included patients admitted for lumbosciatica, explored and treated. Results: Of the 150 lumbosciatica received for 1126 admissions (13.32\%) 95 files were retained. The average age was 52.55 years. The predominance was female with 58 women $(61.05 \%)$ over 37 men. Thirty-two patients $(33.68 \%)$ had exposing occupation due to the prolonged sitting or standing position (i.e., teachers, housewives and accountants). Pains were bilateral in 69 patients $(72.64 \%)$. The lumbo-sacral spine scanner objectified degenerative lesions in $51.13 \%$ of the cases (45 patients). The clinical evolution under analgesic treatment and/or anti-inflammatory, and/or co-analgesics was favorable in $80 \%$ of cases (76 patients), with recurrence in $20 \%$ of cases (19 patients). Conclusion: The socio-economic impacts of lumbosciatica are important due to their recurrence. The treatment is often difficult due to the persistence of residual pain and recurrence. The identification of exposing professions and the education of these populations could prevent this disease by reducing the incidence and improving the patients' life quality.
\end{abstract}

\section{Subject Areas}

Neurology 


\section{Keywords}

The Lumbosciatica, Lumbo-Neuralgic Pain, Iscommon

\section{Introduction}

The lumbosciatica is a lumbar pain with painful distal radiation in the lower limbs of radicular topography L5 or S1 [1]. It most often results from a disco-radicular conflict L4-L5 or L5-S1. The herniated disc is the main cause. It is common and can complicate long past low back pain [2]. The diagnosis is mainly clinical. The diagnosis has become easier thanks to new exploration techniques that are neuroradiology, computed tomography and magnetic resonance imaging (M.R.I). According to a study conducted in neurology consultation at Cocody, lumbosciatica was one of the most common reasons for consultation that is $21.4 \%$ (behind headache (55\%)). They accounted for $57.1 \%$ of all neuralgia [3].

The objective of this study was to identify the socio-demographic, clinical, paraclinical, therapeutic and evolutionary aspects.

\section{Materials and Methods}

We conducted a retrospective, cross-sectional and descriptive study. It included patients received from 1 December 2014 to 28 February 2015 in consultation of Neurology at the University Hospital of Cocody (UHC). Selection criteria concerned all patients admitted for lumbo-sciatica, who were submitted to imaging and treated. The data collection was made by means of an index card of survey. The data collection was made by means of an index card of survey contains the demographic data (age sex occupation), the clinical data, periclinical data, therapeutic data, evolution. The data were seized and analyses by means of the Ear-information 6.00. We informed and obtained the consent of the patients; use of the data in medical purposes and data collection in a anonymous way.

\section{Results}

We selected 95 patients.

\section{Socio-demographic data}

The average age of patients was 52.55 years with extremes of 16 and 83 years. One noted a peak incidence in the age group 45 - 60 years, or $27.36 \%$ (26 patients). The rates were $4.21 \%$ for the age group 16 to 29 , of $25.27 \%$ for 60 to 69 , and $3.15 \%$ for 75 to 90 years. The predominance was female $(\mathrm{n}=58)$ or $61.05 \%$ against $38.95 \%$ of men $(\mathrm{n}=$ 37). The sex ratio $M / F$ was 0.64 .

\section{The occupation}

Temporary worker patients constituted $41.05 \%$ of the cases (39 patients), $12.63 \%$ of household (12 patients), 9.47\% traders ( 9 patients), teachers $6.32 \%$ (6 patients) and the military $5.26 \%$ (5 patients). 


\section{Clinical data}

Consultation deadline: The average of the first consultation was 19.6 months, 1 year and a half after the onset of pain, with extremes of 24 hours and 23 years. The median was at 1 and 2 years (with $10.52 \%$ of the patients each).

Medical history: Lumbosciatica occurred in $58.95 \%$ of cases (56 patients) with no medical history known. It was noted a medical history of heavy loads in $14.73 \%$ (14 patients), a drop of height in $5.20 \%$, and 2 cases of lumbago.

\section{The Types of Lumbosciatica}

The lumbosciatica reported were mechanical in 57 patients (60\%). They were bilateral in 69 patients $(72.64 \%)$, and were located in the L5 area in 32 patients (33.68\%) and S1 in 35 patients $(36.84 \%)$.

The clinical examination revealed a lumbar spinal stiffness in all patients with Lasegue sign whose average level was $47.5^{\circ}$ with a range of $10^{\circ}$ and $90^{\circ}$. At the clinical examination, the root and spinal syndromes were respectively $70.52 \%$ (67 cases) and $100 \%$ (95 cases).

\section{Preclinical data}

\section{Imagery}

The instruments were used to do plain radiographs and computed tomography (CT) in patients are 66 Bars and X-ray scanner. Plain radiographs of the lumbosacral spine were performed in 38 patients (40\%). They objectified a disc disease in 28 patients, in $73.68 \%$ of cases. In $15.79 \%$ of cases, in 6 patients, we noted a spinal deformity ( 2 spondylolystesis, and lordosis, a hump, a kyphoscoliosis, and scoliosis). In 5.27\% of cases there was a nerve root, and one case (2.63\%), sclerotic. The radiography of the spine was normal in $2.63 \%$ of patients.

Computed tomography (CT) scan of the lumbar spine was performed in 88 patients ( $92.7 \%$ of cases). It objectified disc diseases and herniated discs in respectively $22.73 \%$ of cases (20 patients) and $15.90 \%$ of cases (14 patients).

\section{Therapeutic data}

\section{Medications and other prescribed therapeutic}

The medicines names which were used in the treatment of lumbosciatica are paracetamol, paracetamol codeine, paracetamol caffeine, tramadol, diclofenac, ibuprofen, and clonazepam or amitriptyline or Pregabalin in case of pain associated neuropthiques. Drug prescriptions associated 2 molecules in 30 patients (31.58\% of cases). This combination of therapy was made of the combination of analgesic-inhibitors recapture of the serotonin (SRIs) in 22 patients (23.15\%). In $23.15 \%$ of cases (22 patients), the treatment was a monotherapy with an analgesic, a muscle relaxant, an anti-epileptic or a tricyclic antidepressant. In $23.15 \%$ of cases (22 patients), the treatment was a triple therapy, combining such diverse analgesics, anti-inflammatories, antidepressants and / or AEDs, a corticosteroid or a vitamin therapy. In $18.94 \%$ of cases (18 patients), patients received no drug treatment: 14 patients (14.73\%), benefited from physical therapy and in 4 cases, the remission was spontaneous, with rest.

A quadritherapy tuberculosis etiological treatment combining Rifampicin, pyrazi- 
namine, Ethambutol and streptomycin, was undertaken in 3 patients, with spinal tuberculosis epidural.

\section{Evolution}

After a month of treatment, we observed regression of symptoms in a proportion of $80 \%$ (76 patients). In $20 \%$ of cases (19 patients), pain persisted for several months.

\section{Discussion}

Lumbosciatica is a common reason for consultation in neurology. They represent the second cause of consultation after headache. In a study conducted in 2001, they represented $24 \%$ of all consultations with $19.2 \%$ of Neurology neuralgia and $4.8 \%$ of spinal pain. This frequency is probably underestimated given that many patients do not attend hospitals for various reasons. N'Zué et al. reported a hospital prevalence of $38.6 \%$ in 2002 [4]. It was $19.5 \%$ in Togo [5]. A study among hospital staff, said the prevalence of back pain in $11.2 \%$ in relation to $77 \%$ of cases of lumbosciatica [6]. The mean age was 52.55 years in our series. This rate is higher than those of N'Zué et al. Onambany et al., with respectively 42.5 years, and 48 years [4] [7]. These lumbosciatica affect both young people and the elderly. According Kochbati et al. common lumbosciatica is a common pathology nowadays in subjects younger as well as in older patients [7]. Cheour et al. have described lumbosciatica in hospitalized patients over 65 years with a mean age of 71.2 years [8]. In our study, the majority of subjects with lumbosciatica was female. This predominance of female is reported by other authors such as Kpadonoua, Cheour and N'Zué with respectively a sex ratio of $0.66 ; 1.88$ and 0.72 . For others, the predominance of male is clear [7] [9]. N'Zué et al. noted in over half the cases $(69.2 \%)$ that lumbosciatica pain has do with subjects with sedentary work [4]. In our work, the populations most at risk were those with no fixed occupation, or $41.05 \%$ (Table 1). Temporary worker have the highest incidence rate of lumbosciatica because they are several activities at once to save their lives. It was usually people without qualifications, accepting the various work (usually painful, often soliciting the spine) for a generally minimal remuneration, barely covering their daily needs. Thus, $14.73 \%$ of patients (14 cases) were carrying heavy loads. Then come the housewives, shopkeepers and teachers. In the series of Kpadonou et al. in Benin, workers (25.4\%) and office workers $(18.2 \%)$ were the most affected [10]. For Onambany et al., handling represented an occupational risk factor in $20 \%$ of cases [7]. Some authors divide the triggering circumstances of lumbosciatica between effort (48.2\%) and unknown factors (48.2\%) [4]. Thus, in our series, patients were carrying heavy loads in $14.73 \%$ (14 cases) a single case of lumbago was found in the medical history.

The occurrence of lumbosciatica was progressive in all patients (100\%). Choeur in it's series, observed in $93.4 \%$ of cases, a gradual onset [8]. The lumbosciatica was usually bilateral, or $72.64 \%$ in our series (Table 2 ), against $47.6 \%$ in the series of Kpadonou et al. [10]. This bilateralism may be the cause of intermittent lameness in about $45 \%$ of cases [7]. However, the damage can be unilateral, particularly in cases of nerve root compression, as is the case of some degenerative diseases such as herniated disc [8]. It is 
characterized by a unilateral radicular syndrome according to the L5 and S1 paths [7] [11].

Table1. Distribution of patients according to their occupation.

\begin{tabular}{|c|c|c|}
\hline Occupations & Totals $(\mathrm{n}=95)$ & Percentages (\%) \\
\hline Housewife & 12 & 12.63 \\
\hline Trader & 9 & 9.47 \\
\hline Driver & 3 & 3.15 \\
\hline Hairdresser & 2 & 2.10 \\
\hline Teacher & 6 & 6.32 \\
\hline Military & 5 & 5.26 \\
\hline Healthcare agent & 4 & 4.21 \\
\hline Secretary & 2 & 2.10 \\
\hline Student & 2 & 2.10 \\
\hline Librarian & 1 & 1.05 \\
\hline Accountant & 1 & 1.05 \\
\hline Advisor & 1 & 1.05 \\
\hline Assistant trader & 1 & 1.05 \\
\hline Cashier & 1 & 1.05 \\
\hline Legal expert & 1 & 1.05 \\
\hline Diplomat & 1 & 1.05 \\
\hline Retired people & 2 & 2.10 \\
\hline Bus driver & 1 & 1.05 \\
\hline Pastor & 1 & 1.05 \\
\hline Temporary worker & 39 & 41.05 \\
\hline
\end{tabular}

Table 2. Distribution of patients according to the types of lumbosciatica.

\begin{tabular}{cccc}
\hline & Types & Numbers $(\mathbf{n}=\mathbf{9 5})$ & Percentages (\%) \\
\hline \multirow{3}{*}{ Location } & Unilateral & 26 & 27.36 \\
& Bilateral & 69 & 72.64 \\
L4 & 12 & 12.64 \\
L5 & S1 & 32 & 33.68 \\
Time & Not specified & 35 & 36.84 \\
& Mechanical & 7 & 7.36 \\
& Nightly & 57 & 60 \\
Mixt & 17 & 17.90 \\
& Not specified & 6 & 6.32 \\
\hline
\end{tabular}


Plain radiography and CT scans were widely prescribed in our series (Table 3). No patients have realized the magnetic resonance imaging (MRI), due to the low socioeconomic level of our patients. In our series, the most objective injuries to imaging, disk disease were respectively (71.05\%), herniated discs (15.90\%) and spinal deformities (15.79\%). Kochbati et al. also reported a 99\% of degenerative disc disease and $11 \%$ of herniated discs of lumbar spinal stenosis in elderly subjects at least 65 years [12]. But for some authors, the spinal stenosis and herniated disc are common etiologies lumbosciatica as in younger patients than in older patients [7] [8]. Choeur et al. study on common lumbosciatica the elderly, objectified in the lumbar CT, spinal stenosis and herniated disc in the same proportion, $22.7 \%$, and a subsequent joint osteoarthritis in 45.5\%. For others such as Cortet et al., the facet joint osteoarthritis and spinal stenosis were frequent causes of lumbosciatica. Schobeiri et al. report nerve root compressions, ductal strictures, and protrusions disc L4-L5 and L5-S1, respectively in 70\%, 37\%, 29\% and $24 \%$ [13]. Nevertheless, lumbosciatica may fall metastatic tumors of the spine and constituted the primary manifestation [14]. In African countries, the sciatica pain of inflammatory schedule with fever should be investigated first, bone and joint tuberculosis [15]. In our study, 3 of 88 patients showed spondylit is associated with an epidural. For Haddada et al., sciatica in the elderly has some specific clinical traits such as bilateralization, the trip badly systematized, and the frequency of intermittent lameness root. For these authors, should be eliminated in these elderly patients, a secondary lumbosciatica [5]. Indeed, these may be as much lumbosciatica as infectious tumor etiology, even in the elderly.

The therapeutic combination analgesics IRS-like amitriptyline was the most used (22.10\%). It was identified 3 cases of spinal tuberculosis. Patients have benefited from the quadruple tuberculosis associated with corticosteroid therapy. The use of corticosteroids infiltrative way was done in a proportion of $8.42 \%$. According to Valat et al. the epidural are very commonly used in daily practice [8] [16] [17]. Regarding the effectiveness, open studies are numerous and attest a good result in about $65 \%$ of cases [16].

Table 3. Distribution of patients according to the results of lumbar CT.

\begin{tabular}{ccc}
\hline Results & Numbers $(\mathbf{n}=\mathbf{8 8})$ & Percentages (\%) \\
\hline Disc disease & 31 & 35.23 \\
Normal & 14 & 15.90 \\
Disc herniated & 14 & 15.90 \\
Disco-radicular conflict & 10 & 11.36 \\
Deformations & 5 & 5.69 \\
Stenosis canal & 4 & 4.55 \\
Spondylitis with epidural & 3 & 3.40 \\
Collapsed vertebra & 2 & 2.28 \\
Osteocondensation & 1 & 1.14 \\
Sacralisation of L5 & 1 & 1.13 \\
\hline
\end{tabular}


The surgical treatment of herniated disc remains conservative except in cases of lumbosciatica paralyzing, and the syndromes of the ponytail [17]. However, some authors emphasize the effectiveness of physiotherapy, lasting about 3 months on the regression intensity of the lumbosciatica [18]. In some African countries, it is common practice. In Tunisia, al Cheour and associate physical therapy in approximately $45 \%$ of their patients, with favorable developments in $85.7 \%$ of cases [8]. In our study, only 14 patients (14.73\%), benefited from physiotherapy. It should be more often associated with drugs, given the benefit of the pain. However, the very small number of functional rehabilitation centers in public health facilities ( 4 in total) compared to various conditions treated by these centers is an obstacle. The disease is chronic, disabling, marked by episodes of relapses and remissions. Thus, the median age was 1 - 2 years, in our study, with 30 patients (31.57\%) the early pains dated from 1 to 23 years. The average length of evolution of symptoms was greater than that of Breil, which was 9.2 months in its statement on the assessment of compliance with the ANAES recommendations regarding lumbosciatica, [19]. This evolution time even reached 23 years in a patient. This chronicity is likely to disturb the social and professional life of patients.

\section{Conclusion}

The chronicity of lumbosciatica is a clinical reality. The impact of its pain on patients' lives is responsible for a decline in the socio-economic performance. The treatment is difficult because of the persistence of residual pain and recurrence. The high risk factors of lumbosciatica were the occupations at risk and the advanced age. The identification of occupations exposed could help prevent the occurrence of these pains, reduce whenever possible the impact, and improve the quality of the patient.

\section{References}

[1] ANAES (2016) Prise en charge diagnostique et thérapeutique des lombalgies et lombosciatiques communes de moins de 3 mois d'évolution.

http://www.has-sante.fr/portail/jcms/c 267123/fr/lombalgies-communes-de-moins-de-troi s-mois-rpc-2000-rapport-complet-pdf

[2] Aké, M.L. (2008) Bilan des activités en consultations externes du service de Neurologie du CHU de Cocody. Neurologie. Lieu de soutenance de mémoire: Université de sciences médicales, $116 \mathrm{p}$.

[3] Bougoudogo, M. (2006) Aspects épidémio-cliniques et radiologiques des lombosciatalgies au cours des consultations dans le service de Rhumatologie du CHU de Point G. Bamako: Université de Bamako, 68 p.

[4] Ouédraogo, D.D., Eti, E., Daboiko, J.C., Simon, F., Chuong, V.T. and Zué, M.K. (2007) Uncomplicated Herniated Discs and Sciatica: Epidemiologic and Semiotic Aspects in 143 Black African Subjects. Santé, 17, 93-96.

[5] Haddada, F., Ben Hammouda, S., Hassen-Zrour, S., et al. (2005) La sciatique commune du sujet âgé: à propos de 50 cas.

http://www.rhumatologie.asso.fr/Data/ModuleProgramme/PageSite/2005-1/Resume/504.asp

[6] Germanaud, J., Dousset, M. and Bardet, M. (1993) Epidémiologie des rachialgies aigues dans le personnel d'un centre hospitalier. Rachis, 5, 117-120. 
[7] Onambany, B., Esiene, A., Motah, M., et al. (2010) Aspects épidémiologiques, cliniques et thérapeutique du canal lombaire étroit et de la hernie discale lombaire opérés dans les services de chirurgie de l'hôpital de Douala et de l'hôpital d'Hevecam de Niete.

http://www.hsd-fmsb.org/index.php/hsd/article/viewFile/64/pdf 98

[8] Cheour, E., Hamdi, W. and Tekaya, R. (2007) Common Lumbosciatic Syndrome of Elderly. Report of 67 Cases. Tunisie Médicale, 85, 549-552.

[9] Sanoussi, S., Bawa, M., Maman Sani, R., et al. (2005) Prise en charge du canal lombaire étroit à Niamey. Journal NeurosurgySpine, 2, 624-633.

[10] Kpadonou, G.T., Alagnidé, E., Gbénou, S., Fiossi-Kpadounou, E., Houngbedji, G., Niama, D., et al. (2012) Récidives des lombosciatalgies communes au Bénin. Revue d'Epidémiologie et Santé Publique, 55, 282-289. http://dx.doi.org/10.1016/j.rehab.2012.07.726

[11] Cortet, B. and Bourgeois, P. (1992) Causes and Mechanisms of Sciatic Pains. Revue du praticien, 42, 539-543.

[12] Kochbati, S., Daoud, L., Jemni, C., et al. (2008) Lombosciatiques communes du sujet âgé. Dans Société française de Rhumatologie, France [enligne]. http://poster.rhumatologie.asso.fr/ModuleConsultationPoster/posterDetail.aspx

[13] Schobeiri, E., Khalatbari, M.R., Taheri, M.S., Tofighirad, N., et al. (2009) Magnetic Resonance Imaging Characteristics of Patients with Low Back Pain and Those with Sciatica. Singapore Medecine Journal, 50, 87-93.

[14] Abril Martin, J.C., Calvo Crespo, E., Alvarez Galovich, L., et al. (1993) Malignant Lumbosciatic Syndrome. Report of 21 Cases with Vertebral Metastases. Revue Clinique Espanol, 193, 131-135.

[15] Lazrak, F., Elouazzani, F., Abourazzak, F., et al. (2012) Tuberculose sacrée, une localisation rare: à propos de 3 cas. Dans Société française de Rhumatologie, France [en ligne]. http://poster.rhumatologie.asso.fr/ModuleConsultationPoster/posterDetail.aspx?intIdPoste $\underline{r=2364}$

[16] Valat, J.P. and Rozenberg, S. (2008) Les infiltrations de corticoide dans les lombosciatalgies et les lombalgies communes. Revue du rhumatisme, 75, 590-595. http://dx.doi.org/10.1016/j.rhum.2008.02.007

[17] Pallazo, E. and Kahn, M.F. (1992) Non Surgical Treatment of Disk-Related Sciatica. Revue du praticien, 42, 573-578.

[18] Eyenga, V.C., Ngowe, N.N., Minkande, J.Z., et al. (2008) Kinetics of Regression of Sciatic and Pain in the Low Back after Lumbar Macrodiscectomy in Human Immunodeficiency Virus Carriers. Spine (Phila Pa 1976), 33, 411-413. http://dx.doi.org/10.1097/BRS.0b013e318175c32b

[19] Breil, D. (2007) Respect des recommandations de l'ANAES, en médecine générale, dans la prescription des examens complémentaires des lombalgies de moins de 3 mois d'évolution. Faculté de Médecine de Créteil, Paris XII, 48 p. 
Submit or recommend next manuscript to OALib Journal and we will provide best service for you:

- Publication frequency: Monthly

- 9 subject areas of science, technology and medicine

- Fair and rigorous peer-review system

- Fast publication process

- Article promotion in various social networking sites (LinkedIn, Facebook, Twitter, etc.)

- Maximum dissemination of your research work

Submit Your Paper Online: Click Here to Submit

Or Contact service@oalib.com 